\title{
Fronto - temporal approach in sellar and parasellar tumors
}

\author{
Bianca Pintea $^{1}$, Andreea Mogyoros ${ }^{2}$, Zorinela Andrasoni ${ }^{2}$, I.St. Florian ${ }^{3}$ \\ ${ }^{1} \mathrm{PhD}$ student, "Iuliu Hatiaganu" UMPh, Cluj-Napoca \\ ${ }^{2}$ Cluj-Napoca Emergency Hospital \\ 3"Iuliu Hatiaganu" UMPh, Cluj-Napoca
}

\section{Abstract}

Introduction: The fronto-temporal approach represent the shortest distance to the ipsilateral optic nerve and carotid artery, and allow the direct verification of the optical nerves, the carotid arteries, the pituitary stalk, the tumor and its relationship with the suprasellar structures.

Objective: The purpose of this study is to advocate an available cranial base technique for removing these tumors and to delineate the technique's advantages that aid in achieving an improved extent of tumor resection and enhancing the patients' overall outcome.

Materials and methods: We present a retrospective study of a single surgeon experience on 355 consecutive cases with sellar and parasellar tumors admitted and operated by transcranial approaches in our department between January 2000 and December 2012.

Results: Tumors in the sellar region represent $11,8 \%$ of all tumors operated in our department. The most common type of tumor was pituitary adenomas, 165 of cases, followed by sellar and parasellar meningiomas, 128 of cases. Craniopharyngioma represent $12 \%$ of cases encountered in this region.

All our cases underwent surgery by transcranial approach, unilateral fronto- temporal in 252 of cases (71\%). In pituitary adenomas total and near total resection was achieved in $100 \%$ of patients operated by transcranial approaches. For resection of craniopharyngiomas we have frequently chosen the extended fronto-temporal approach.

The most common surgical related complications were: postoperative hematomas 9 of cases; wound infections, 6 of cases and CSF leakage, 12 of cases; transient visual alteration in 12 cases, transient third cranial nerve palsy in 6 of cases, transient motor deficit in 7 cases, hydrocephalus, 6 cases; transient diabetes insipidus in the large majority of pituitary adenomas and craniopharingiomas. Only 4 cases of pituitary adenomas and 6 of craniopharingiomas recurred after subtotal resection, requiring re-intervention. The mortality rate in our study was $2 \%$.

Conclusions: Our experience demonstrated that the management of the large suprasellar tumors via fronto-temporal approach remains the main route for these tumors with significant extrasellar extension, fibrous tumors, cases with unrelated pathology that might complicate a transsphenoidal approach and recurrent tumors after previous transsphenoidal surgery. In our opinion there is no need for larger osteotomies or extensive drilling of 
cranial base. "Instead of bone, remove the tumor; it's easier even for the patient".

Key words: craniotomy, extent of resection, fronto-temporal approach, pituitary adenomas, suprasellar meningiomas

\section{Introduction}

Sellar and parasellar tumors are challenging lesions to resect completely and safely. In nowadays neurosurgery when endoscopic endonasal techniques have gained more and more indications, the classical intracranial approach seems to decrease in importance. But there are still numerous indications for intracranial approach, especially related to the size, extension and involvement of neurovascular structures in the region. Most of the lesions approached intracranial are large tumors, so they are life threatening, they compress optic pathways, engulf carotid arteries and their ramifications, obstruct CSF circulation and disturb the functions of pituitary gland and hypothalamus. Sometimes do to their dimensions they alter the cognitive functions of frontal lobes. $(3,13,17)$ By removing this tumor totally our intension is to preserve or sometimes to restore the normal function and to salvage the life of the patients. Selection of the approach is based on the size, configuration, location and extent of the tumor. Recent advances in cranial base exposures, microsurgical techniques, neuroimaging, neuronavigation and neuroanesthesia have resulted in an improved extent of resection and patient outcome. $(1,4,18)$

The fronto-temporal approach (aka fronto-pterional) has the great advantage to be very familiar to most of neurosurgeons, represent the shortest distance to the ipsilateral optic nerve and carotid artery, and allow the direct verification of the optical nerves, the carotid arteries, the pituitary stalk, the tumor and its relationship with the suprasellar structures. By opening of the entire Sylvian fissure this approach offers multiple ways to reach de sellar region: prechiasmatic, suprachiasmatic, trans-lamina terminalis, between ON and ICA, lateral to ICA, above the ICA bifurcation, representing the widest used techniques in today's neurosurgery practice. $(4,6,11)$

Based on our experience, there is no need for larger opening for multidirectional approach because that means multiple ways for brain injury. The key points are proper positioning, proper opening, brain relaxation and surgical experience. Yasargil was credited to the standard and maybe the most important approach, pterional or fronto-temporal approach. Many modifications of this approach by new neurosurgeons have been created. $(22,23)$

\section{Objective}

The purpose of this study is to advocate an available cranial base technique for removing these difficult tumors and to delineate the technique's advantages that aid in achieving an improved extent of tumor resection and enhancing the patients' overall outcome. We aim to describe our experience in the last 10 years concerning the surgery of sellar and parasellar tumors using fronto-temporal approach.

\section{Materials and methods}

We present a retrospective study of a single surgeon experience on 355 
consecutive cases with sellar and parasellar tumors admitted and operated by transcranial approaches in our department between January 2000 and December 2012. We discussed the tumor's characteristics that could influence the treatment decision and the choice of the most reliable approach.

\section{Surgical approach}

Frontopterional approach is fashioned according to the tumor dimensions and extensions. The patient positioned supine with the head turned about 15 degrees for subfrontal approach, $30^{\circ}$-pterional approach, to the opposite side along the ala minor of the sphenoid wing and slightly retroflexed about $10^{\circ}$. The scalp incision starts just anterior to the tragus, behind the superficial temporal artery then it continue superiorly behind the hairline towards the midline; interfascial dissection to preserve the frontal branch of the facial nerve. Frontal burr hole is performed at maximum $3 \mathrm{~cm}$ anterior to "key hole", with bone removal extending to the skull base anteriorly. Before dural opening the lumbar drainage is opened and in few minutes a good brain relaxation is obtained. The dura is opened in a semicircular fashion, centered on the pterion. Using only the microsurgical aspirator and a bayoneted forceps we enter subfrontal until the optic nerve, which is the most constant landmark. The arachnoid above the $\mathrm{ON}$ is sharply opened and than dissection goes medially and laterally in order to gain more space. With the opening of the basal cisterns the brain is relaxing progressively and offers enough space for microsurgical exploration of the entire region.

\section{Results}

Tumors in the sellar region represent 11 , $8 \%$ of all tumors (3006 cases) operated between January 2000 and December 2012. There is a significant female predominance (M/F $46 \%$ vs. $56 \%$ ) with a sex ratio of $1,28$. (Graphic 2) The peak incidence was in the 5th decade. (Graphic 3)

In a pathological point of view, the most common type of tumor in our study was pituitary adenomas, 165 of cases (46\%), followed by sellar and parasellar meningiomas, 128 of cases (36\%). We classified the meningiomas in this region in the median group (tuberculum, diaphragma, planum sphenoidale) 66 of cases and lateral group (clinoidal, sphenoorbital, spheno-cavernous) 62 of cases. Craniopharyngioma represent $12 \%$ of cases encountered in this region (42 of cases). Other tumors were represented by low grade gliomas of the optic pathway and hypothalamus (8 cases $-2 \%$ ), germ-cell tumor 4 cases $(1 \%)$, metastasis 3 cases $(1 \%)$, Rathke cleft cyst 3 of cases (1\%) and 2 cases of immature teratoma (1\%). (Graphic 1) At the pediatric age approximately half of all suprasellar tumors are craniopharyngiomas, compared with only $10 \%$ in adults.

Regarding the clinical presentation, headache and eye pain were present in $80 \%$ of cases. The most common ophthalmic disturbance was blurred vision, in $68 \%$ of cases, followed by visual field defect uni/bilateral hemianopia in $42 \%$ of cases and diplopia in $28 \%$ of cases. Except the cases with pathological hypersecretion from functional pituitary adenomas, a certain grade of pituitary hipofunction was detected $26 \%$ cases. 
Other signs were memory impairment $(20 \%)$ and seizures in only $5 \%$ of the cases. (Graphic 4) The mean duration of symptoms was 11, 5 months. (Graphic 5)

All our cases underwent surgery by transcranial approach, unilateral frontotemporal in 252 of cases $(71 \%)$, unilateral subfrontal in 64 of cases (18\%), bifrontopterional in 14 of cases (4\%), bifrontal in 10 of cases (3\%), interemispheric transcallosal in 9 of cases $(3 \%)$ and frontoorbitozigomatic in 3 of cases (1\%). (Graphic 6)

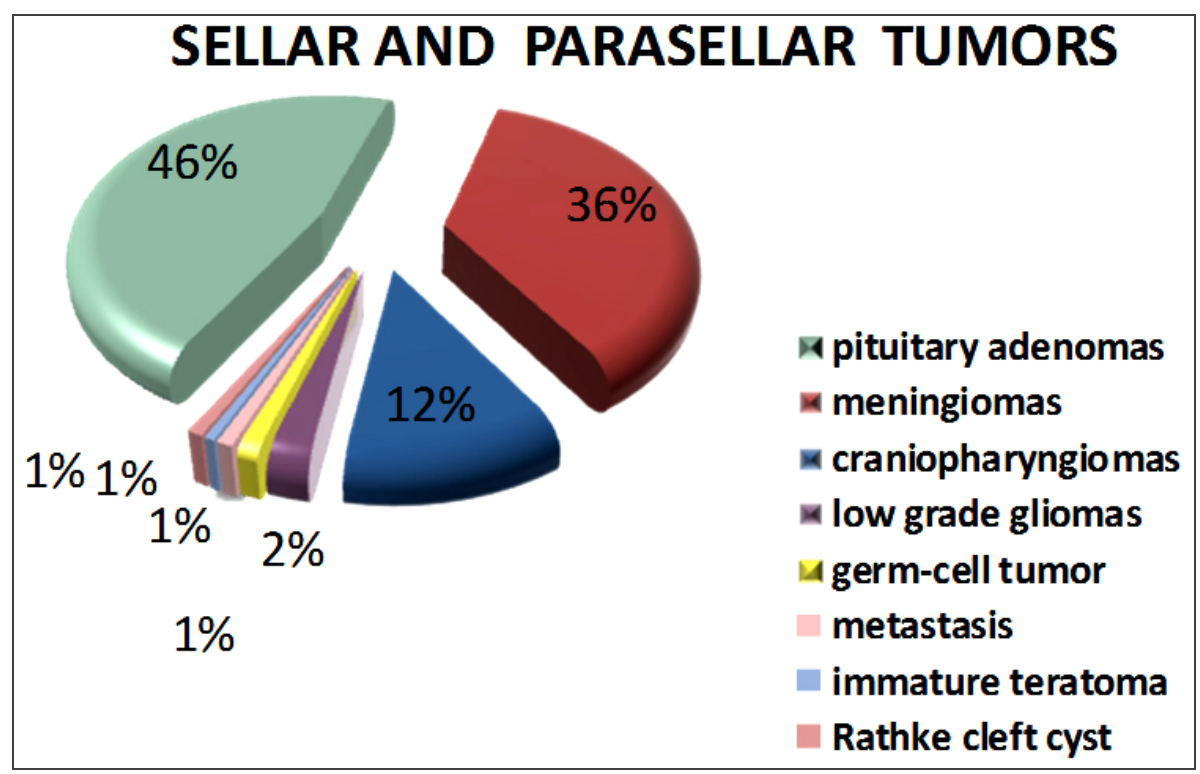

Graphic 1. Type of tumors

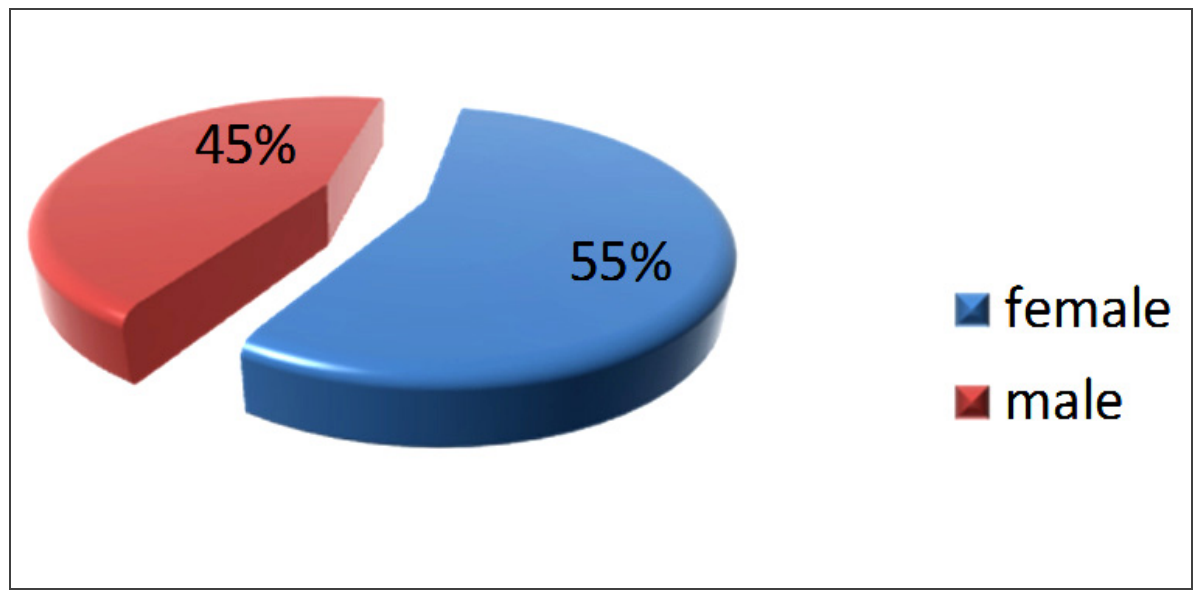

Graphic 2. Sex ratio 


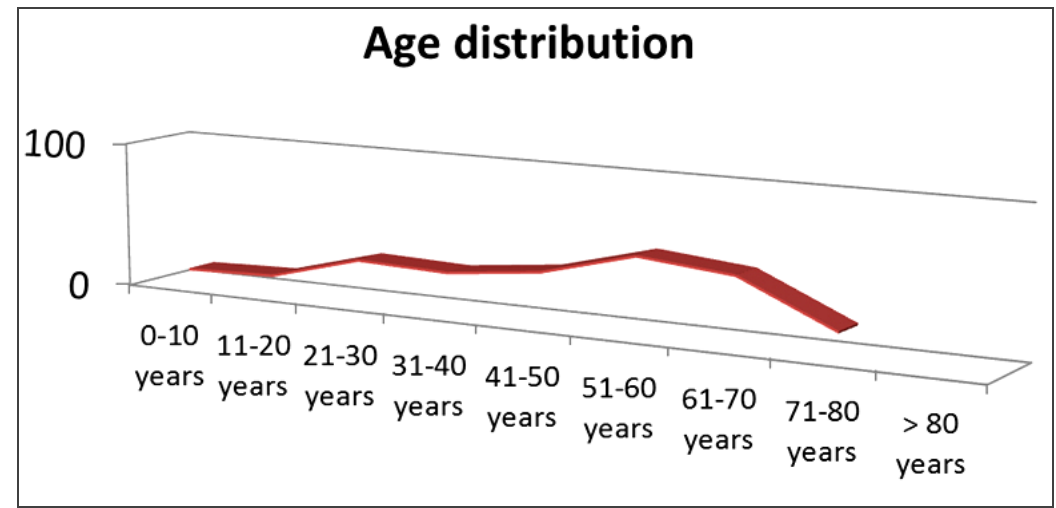

Graphic 3. Age distribution (Peak incidence in the 5th decade)

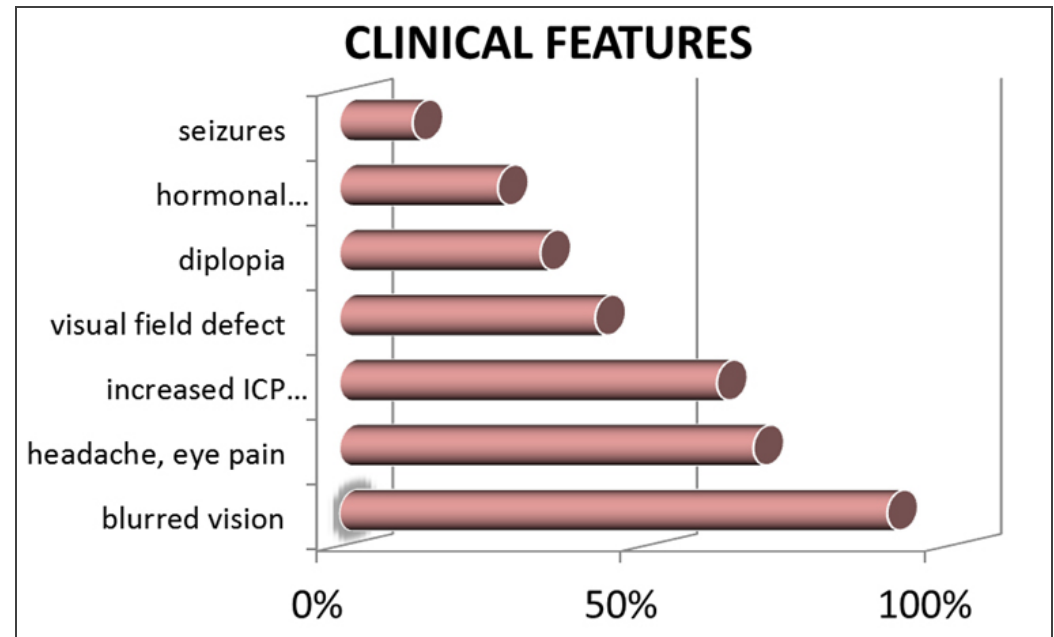

Graphic 4. Clinical features

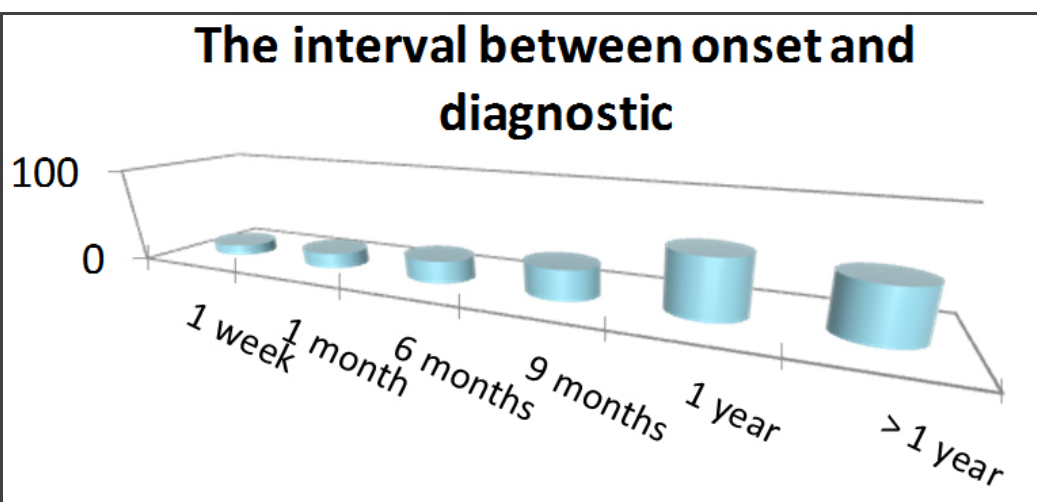

Graphic 5. The interval between onset and diagnostic 


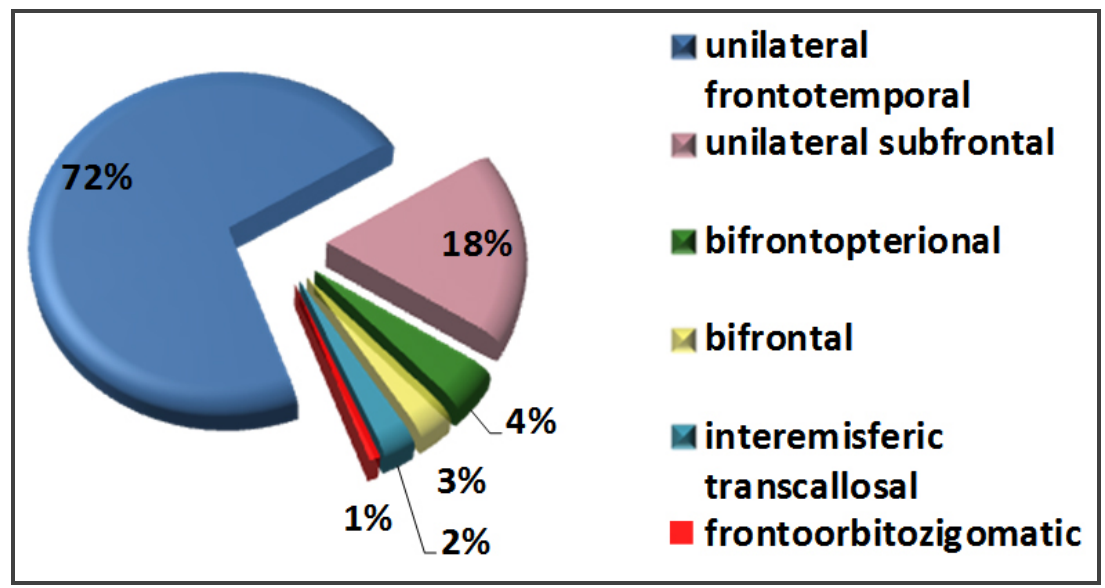

Graphic 6. Surgical approaches

All the patients of sellar and parasellar meningiomas underwent surgery by transcranial approach; modified frontopterional approach was performed in majority of cases and total resection was achieved with minimal complications. In 118 patients (92\%) complete tumor removal was achieved, total resection being confirmed by postoperative MRI scans. We must underline that in this region complete removal is in the large majority of cases a grade II according to Simpson's classification, this being more available in diaphragmal meningiomas. In many cases removal of involved dura along with hiperostotic bone was possible, but there are still regions of dura mater with pathological neovascularisation that could not be removed and it was only coagulated. Recurrences have been found in 6 cases of clinoidal and spheno-cavernous meningiomas. Three cases died after the surgery, in all cases being reintervention after previous operated spheno-cavernous meningiomas. (Figure 1A, B; Figure 2A, B; Figure 3A, B)

In pituitary adenomas total and near total resection (fragment of capsule adherent to the chiasm, residual tumor on the floor of the sella, fragments infiltrating the cavernous sinus discovered at the postoperative MRI) was achieved in $100 \%$ of patients operated by transcranial approaches. (Figure 4A, B)

For resection of craniopharyngiomas we have frequently chosen the extended fronto-temporal approach (57\%); all other cases have been approached transcallosal interemispheric or subfrontal interemispheric by bifrontal craniotomy; bifrontopterional craniotomy and combined routes were reserved for multidirectional approach of giant tumors. Gross total removal was achieved in over half of cases. Reasons for incomplete resection were a firm adherence to hypothalamus, large calcifications, and adherence to perforating vessels or greater vessels from the polygon of Willis. (Figure 5A, B), (Figure 6A, B, C, D)

Surgical related complications were: local (postoperative hematomas, 9 of cases; wound infections, 6 of cases; ICA tearing, 3 of cases and CSF leakage, 12 of cases) and neurological (transient visual alteration in 12 cases, transient third cranial nerve palsy in 6 of cases, anterior cerebral artery vasospasm in two of cases, transient motor 
deficit in 7 cases, cerebral infarction in 3 cases, hydrocephalus, 6 cases; transient diabetes insipidus in the large majority of pituitary adenomas and craniopharingiomas. Only 4 cases of pituitary adenomas and 6 of craniopharingiomas recurred after subtotal resection, requiring re-intervention. (Table 7)

The mortality rate in our study was $2 \%$.

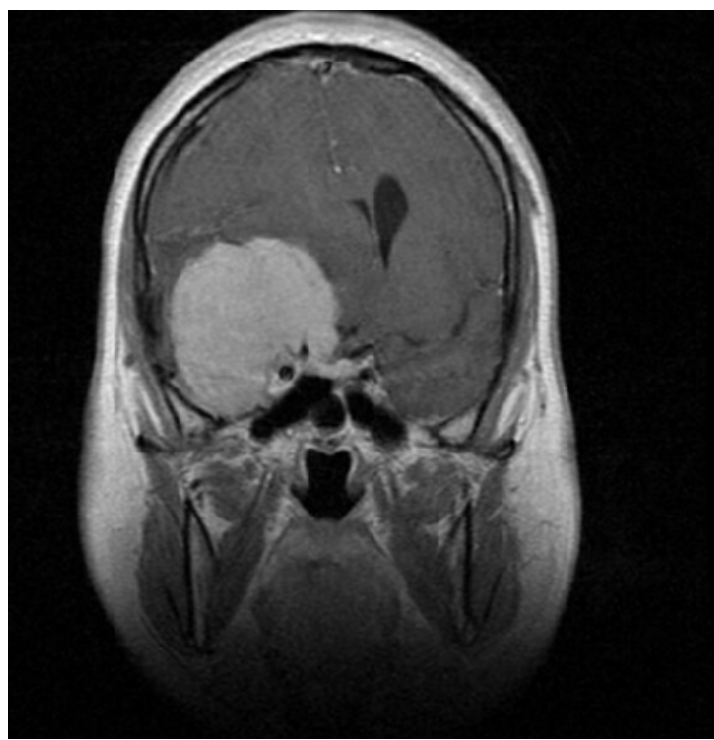

A

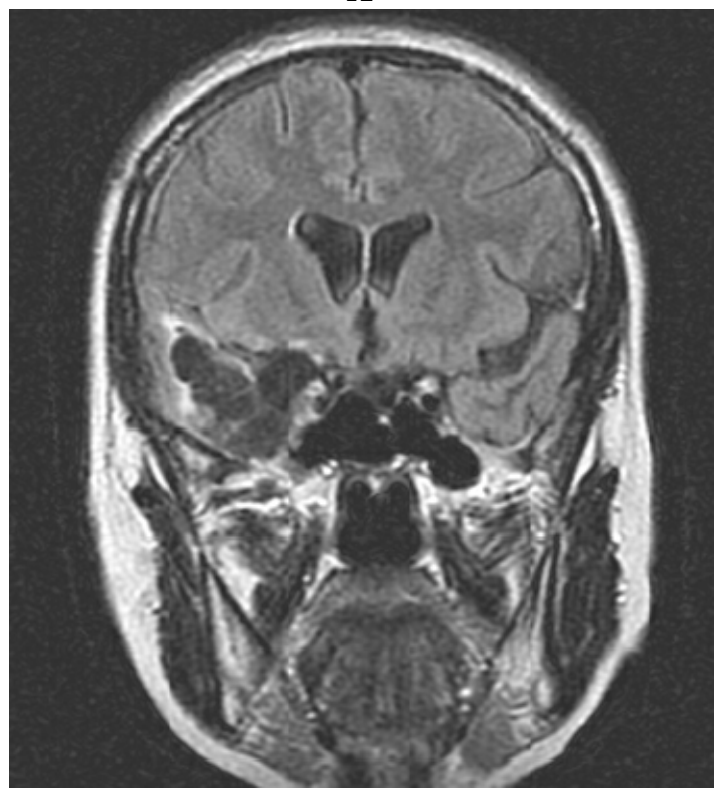

B
Figure 1 A, B Clinoidal meningioma T1 weighted contrast enhanced sagital MRI shows a large clinoidal meningioma that invades the lateral wall of the cavernous sinus and incorporates carotid artery at this level; postoperative MRI shows complete removal of the tumor
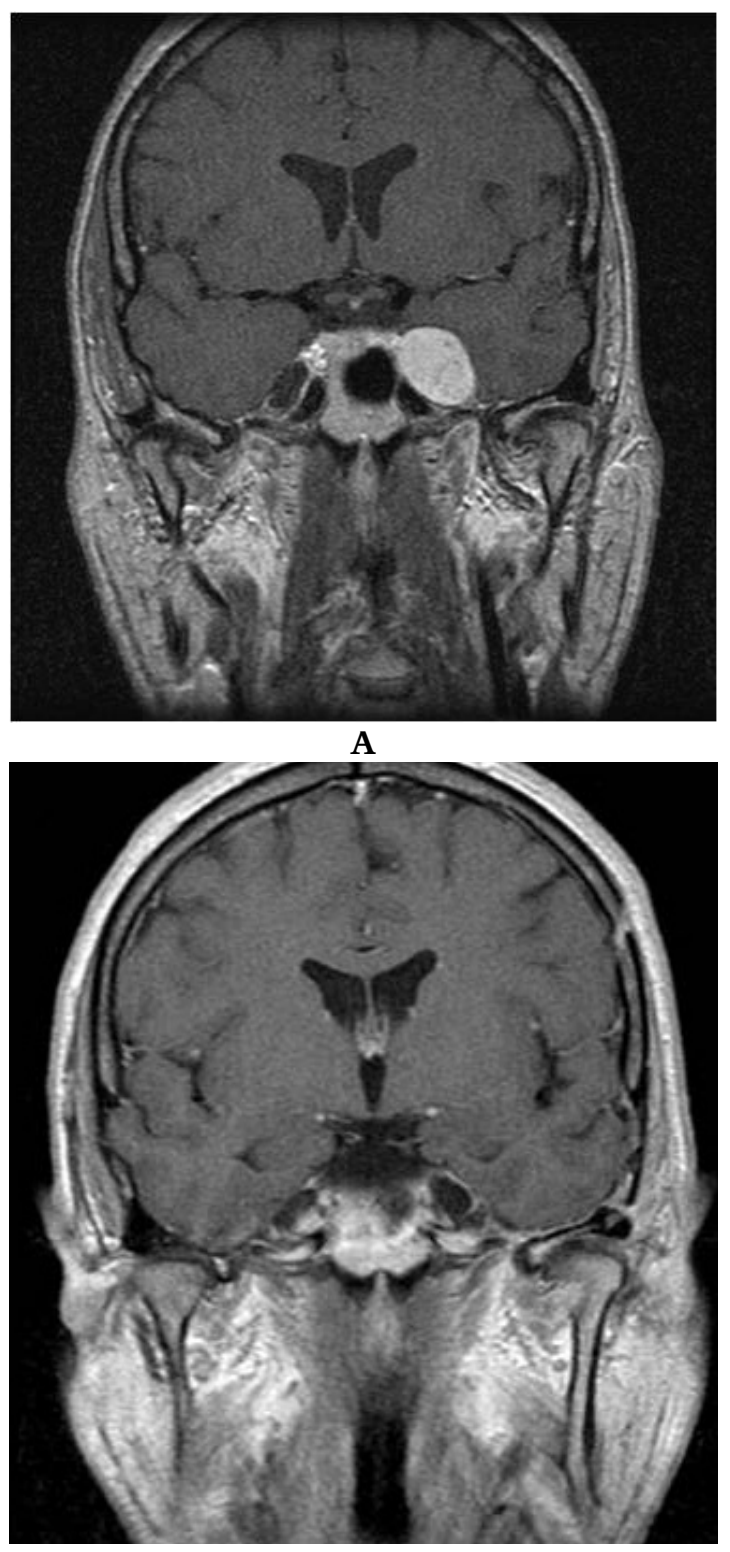

B

Figure 2 A, B Spheno-cavernous meningioma Preoperative and postoperative T1 W enhanced sagital MRI showing a left sphenocavernous meningioma completely removed by a pterional approach 


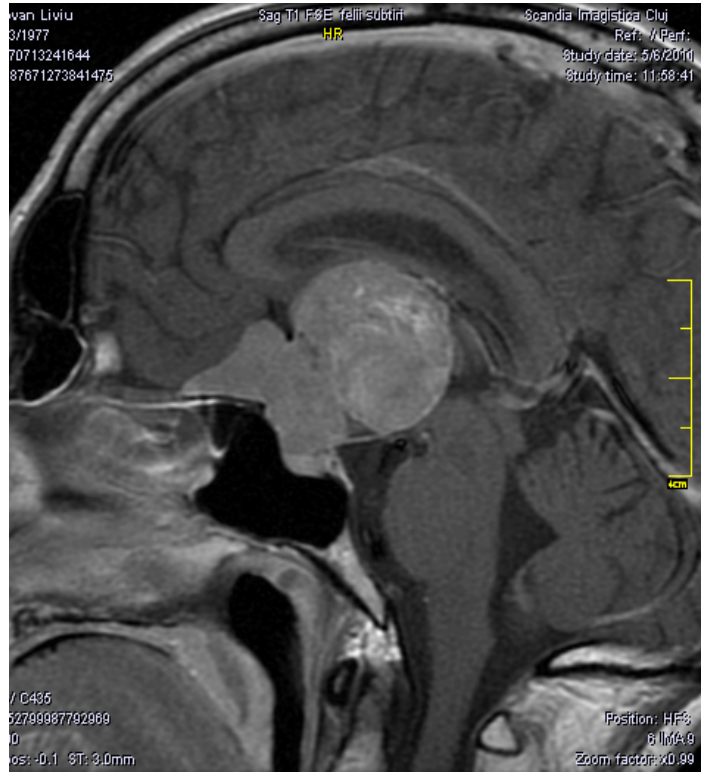

A

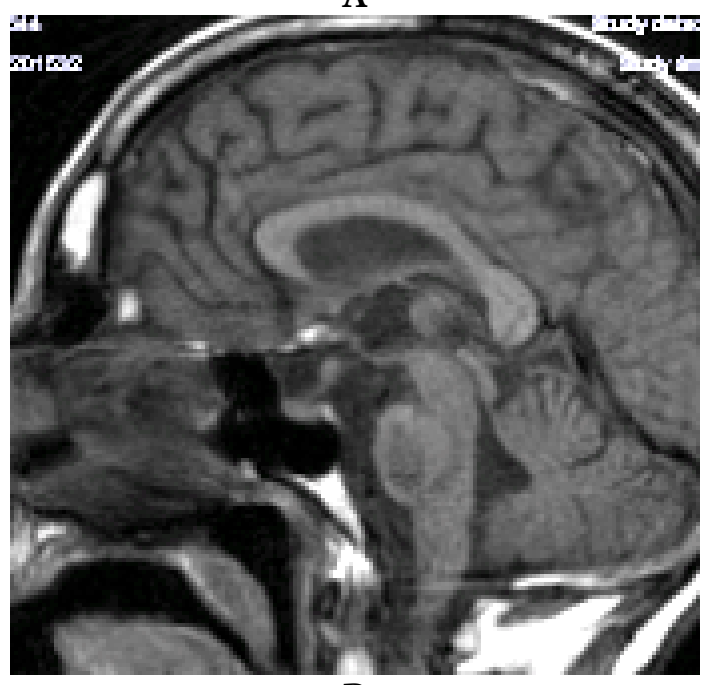

B

Figure 3 A, B Suprasellar meningioma

T1 weighted contrast enhanced sagital MRI demonstrating giant suprasellar meningioma with superior extension in third ventricle and posterior in perimesencephalic cistern, completely removed by a fronto-temporal approach as is demonstrated by third month follow -up MRI

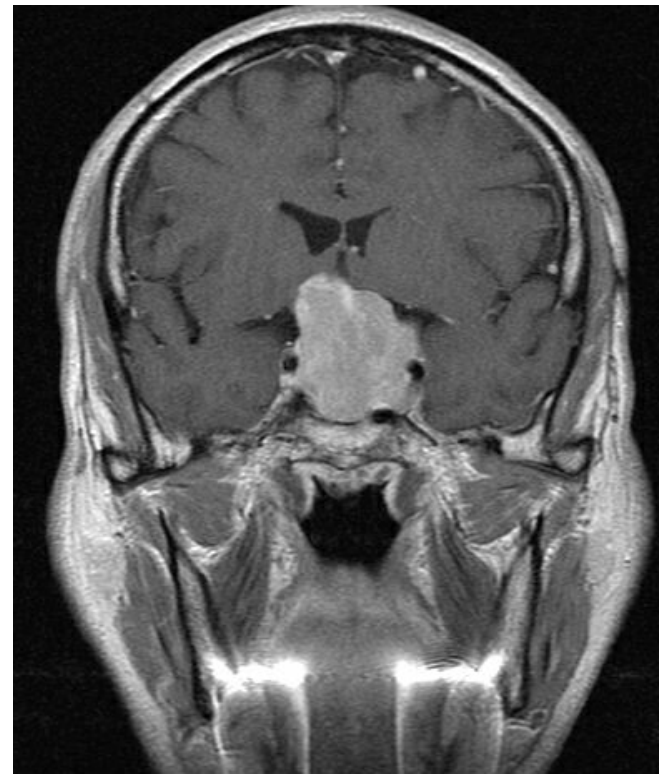

A

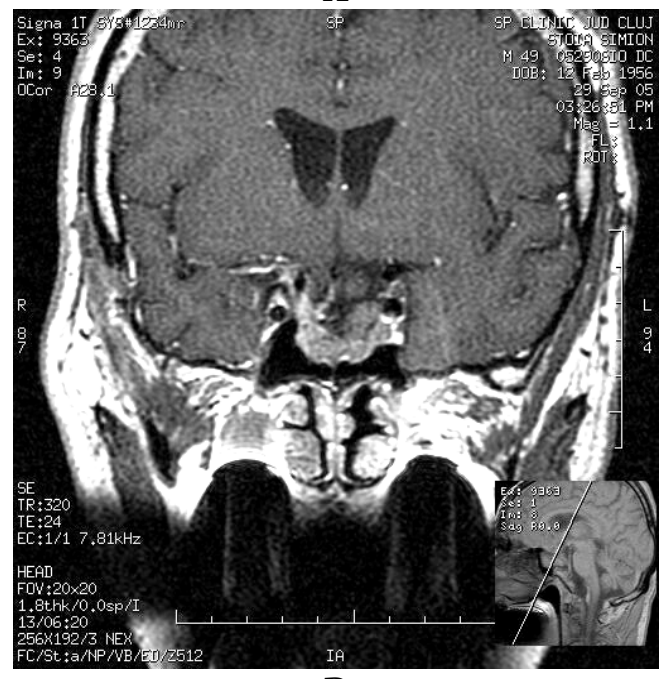

B

Figure 4 A, B Pituitary adenoma

T1W enhanced MRI in a macroprolactinaoma near total removed by a fronto-temporal approach. The intrasellar remnant is stable after six years, without adjuvant radiotherapy 


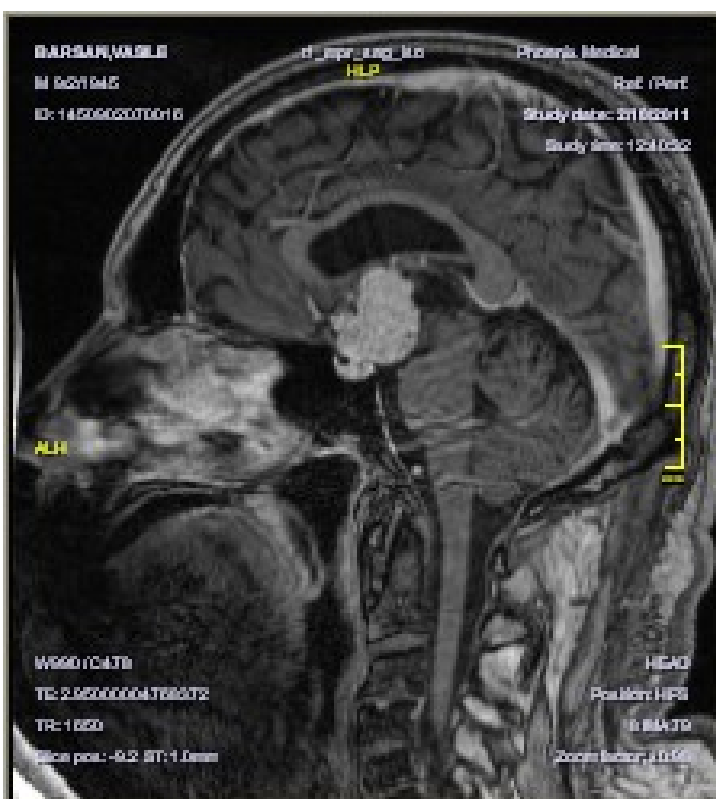

A

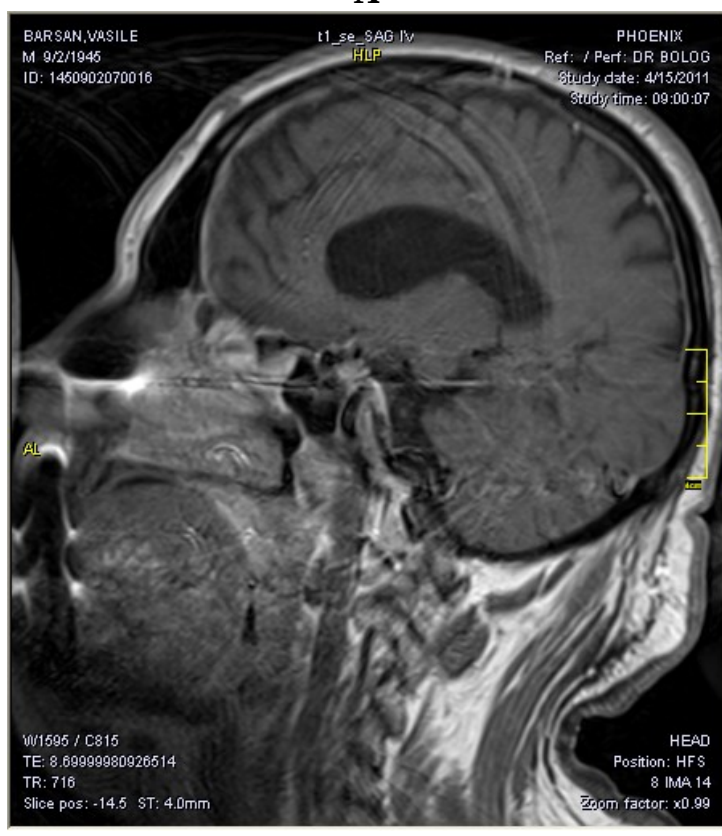

B

Figure 5A, B Craniopharyngiomas

Preoperative MRI showing a suprasellar solid craniopharyngioma extending from the infudibular area into the third ventricle, removed completely by fronto-temporal approach

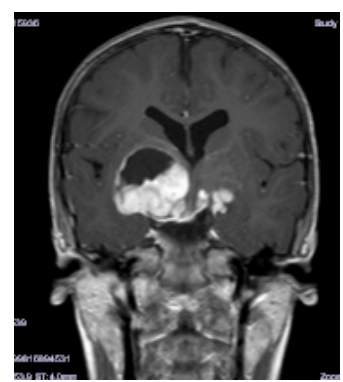

A

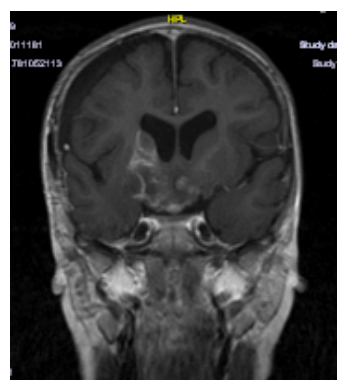

C

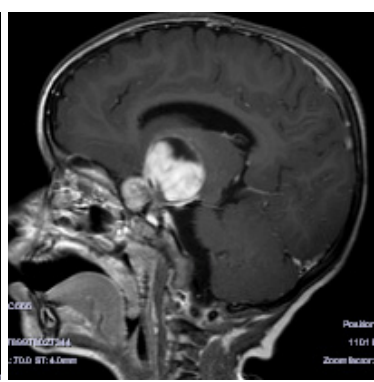

B

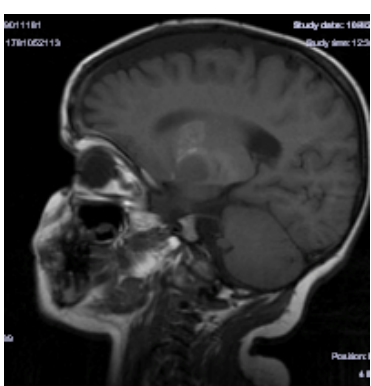

D
Figure 6 A, B, C, D Diencephalic glioma Pre and postoperative MRI aspect to a 3 years old child with an opto-diencephalic glioma with malignant transformation. The 24 hour postoperative MRI demonstrate a near total removal, performed by a fronto-temporal approach

\section{TABLE 7}

Surgical complications

\begin{tabular}{|c|c|}
\hline Complications & $\begin{array}{c}\text { No. of } \\
\text { cases }\end{array}$ \\
\hline Transient diabetes insipidus & 57 \\
\hline CSF leak & 12 \\
\hline Worsen of visual deficits & 12 \\
\hline Transient motor deficit & 7 \\
\hline Transient third cranial nerve palsy & 6 \\
\hline Hydrocephalus & 6 \\
\hline Infection of surgical wound & 6 \\
\hline Intracerebral hematoma & 9 \\
\hline Anterior cerebral artery vesospasm & 3 \\
\hline ICA tearing & 3 \\
\hline Cavernous sinus injury & 1 \\
\hline
\end{tabular}




\section{Discussion}

This study presents the favorable surgical outcomes when using a frontotemporal approaches for sellar and parasellar tumors. In particular, their midline location and encasement of neurovascular structures create challenges for access. The delicacy of microsurgical techniques relieves the surgical outcome for patients with parasellar region lesions, leading to improved survival and quality of life. $(1,4,18)$

There are many publications of surgical approaches for the tumors of this area since its first report. All of these approaches have their advantages and disadvantages, but in the present time only several approaches are popular among neurosurgeons, those are pterional, unilateral frontal, frontolateral, bifrontal, and their modifications, and transsphenoidal. $(3,12,15)$

The first fronto lateral craniotomy was described by Dandy in 1933 to expose the optic chiasm and the pituitary region and was later refined by Kempe (6, 9, 23). The Yasargil's classical description of pterional craniotomy centered in fronto-temporal fissure was first popularized in 1970 and has been widely used to approach lesions of the sellar or suprasellar region, Circle of Willis and Sylvian fissure. (8, 17, 19) This approach consists of accessing the brain and the anterior skull base through their lateral aspect by removing the frontal and temporal bones and the lateral two thirds of the lesser sphenoid wing, including the microsurgical dissection and opening of the sylvian fissure and cistern. $(13,21,22)$

Several variants of this technique have been proposed to reduce the bone flap of the pterional craniotomy and to limit functional and aesthetic complications.

Chehrazi, in his study of 1992, proposed fronto-lateral craniotomy located entirely underneath the temporal muscle that extends about $3.0 \mathrm{~cm}$ beyond pterion, which required extensive dissection of muscle temporal with functional and cosmetic implications. (2) In 2006 Figueiredo demonstrated that the distal dissection of the Sylvian fissure offered no extra benefits for anatomical exposure of the neurovascular structure from this area. $(6,7)$

Regarding the position, there are no debates: supine with head rotate to opposite site $15-30^{\circ}$ (15 degrees for subfrontal approach, $\quad 30^{\circ}$-pterioanal approach). Moderate hyperextension is needed as is the elevation of the head from the heart level.

As far as we are concerned, whenever there is an suprasellar extension that adheres intimately to optic nerves, the carotid, or reaches the level of third ventricle, although situated in the direction of possible transphenoidal approach, we prefer a surgical decompression a "at sight ", by intracranial approach. The bone flap position can be modified anteriorly, posteriorly or in length, depending on the localization of the tumor in which to provide an optimal access to the lesions with minimal retraction of the brain. (20)

The goals of surgery for suprasellar meningiomas are to perform as complete a removal as possible with preservation of visual function and normalize any hormonal abnormalities. $(10,16,18)$ The best approach to use depends on the anatomic location or spread of the tumor, along with a degree of familiarity and confidence that the surgeon has with a given approach. Most suprasellar meningiomas can be removed completely and safely. The most used surgical approach is the standard fronto-temporal approach, 
with preservation and even improvement of visual function after surgery. This approach has the considerable advantage of facilitating complete resection of dural tails thereby preventing recurrence, and it provides reliable surgical procedures for treatment of anterior skull base meningiomas. $(5,16,19)$

When a pituitary adenoma meets the indications for transcranial approach, the approach must still be tailored according to the direction and the extend of extrasellar tumor, the reasonable goals of surgery, the particular experience of the surgical team.

In our experience, radical resection of $\mathrm{CPH}$ represented the first and almost unique treatment modality. Although not insignificant, post-operative mortality and morbidity do not seem to represent a major contraindication in attempting a radical tumor resection whenever possible. On the other hand, extensive hypothalamic involvement should suggest a less aggressive attitude. $(9,14,21)$

The ultimate goal of total resection consists in no recurrence while avoiding complications, is often difficult because of: involvement of vital neural and/or vascular structures; invasion of the bony tissue; poor delimitation; increased malignancy. (20)

\section{Conclusions}

Our experience demonstrated that the management of the large suprasellar tumors via transcranial approach remains the main route for these tumors with significant extrasellar extension (in the middle fossa, posterior fossa or suprasellar), fibrous tumors, cases with unrelated pathology that might complicate a transsphenoidal approach (infections of the sphenoid sinus, parasellar aneurysms) and recurrent tumors after previous transsphenoidal surgery.
We agree that complete microsurgical removal, when safe, is the treatment of choice that offers the best chance of cure. Overall, craniotomies will continue to play a role in the management of patients with sellar/parasellar tumors, although patient selection and careful preoperative evaluation are key elements in choosing the most appropriate approach.

In our opinion there is no need for extensive craniotomies in the large majority of the cases. A proper positioning, good brain relaxation, appropriate microsurgical technique and instrumentation and surgical experience are the key elements for a complete removal of the tumor. By progressive debulking we gain more and more space for tumor mobilization and removal. "Instead of bone, remove the tumor; it's easier even for the patient"

\section{References}

1.Aydin, I. H.; Takçi, E.; Kadioğlu, H. H. et all,: Pitfalls in the Pterional Approach to the Parasellar Area (Review) ${ }^{\star}$ min - Minimally Invasive Neurosurgery; Issue 04, 1995

2.Chehrazi BB: A temporal transsylvian approach to anterior circulation aneurysms. Neurosurgery 30:957961, 1992.

3.Day JD Surgical approaches to suprasellar and parasellar tumors. Neurosurgery Clinics of North America 14 109-122, 2003

4.De Oliveira E, Siqueira M, Tedeschi H, Peace DA. Technical aspects of the fronto-temporo-sphenoidal approach craniotomy. In: Matsushima T (Ed). Surgical anatomy for microneurosurgery VI: cerebral aneurysm and skull base lesions. Fukuoka City: Sci Med Publications: 3-8, 1993

5.Fahlbusch R, Schott W. Pterional surgery of meningiomas of the tuberculum sellae and planum sphenoidale: Surgical results with special consideration of ophthalmological and endocrinological outcomes. J Neurosurg.96:235-43, 2002

6. Figueiredo EG, Oliveira AM, Plese JP, Teixeira MJ. Perspective of the frontolateral craniotomies. Arq Neuropsiquiatr 68:430-432, 2010

7.Figueiredo EG, Deshmukh P, Zabramski JM, Preul MC, Crawford NR, Spetzler RF. The pterionaltranssylvian approach: an analytical study. 
Neurosurgery 2006; 59:263-269.

8.Heuer GJ. The surgical approach and treatment of tumors and other lesions about the optic chiasm. Surg Gynecol Obstet 53: 489-518, 1931

9.Hoffmann HJ, Craniopharyngiomas: the continuing controversy on management. Concepts Pediatr Neurosurg 2: 14-28, 1982

10.Jallo G, Benjamin V. Tuberculum sellae meningioma: Microsurgical anatomy and surgical technique. Neurosurgery. 51:1432-40, 2002

11. Kim E, Delashaw JB Jr. Osteoplastic pterional craniotomy revisited. Neurosurgery. 68:S125-S129, 2011

12.Knosp E. Practical Handbook of Neurosurgery from Leading Neurosurgeons. In: Sindou M, editor. Springer Verlag: New York; pp. 79-94, 2009

13.Liu JK, Weiss MH, Couldwell WT: Surgical approaches to pituitary tumors. Neurosurg Clin N Am 14:93-107, 2003

14.Nakamura M, Samii M. Berlin, Heidelberg: Springer Verlag; 2008. In: Ramina R, Aguiar PH, Tatagiba M, editors. Samii's Essentials in Neurosurgery. Springer Verlag: Berlin Heidelberg; pp. 98-105, 2008.

15.Nakamura M, Roser F, Struck M, Vorkapic P, Samii M. Tuberculum sellae meningiomas: Clinical outcome considering different surgical approaches. Neurosurgery.59:1019-29, 2006

16. Oreste de Divitiis, Enrico de Divitiis. Anterior
Cranial Fossa Meningiomas: A New Surgical Perspective. World Neurosurgery 77:5-6, 623-624, 2012 17.Samandouras G, Kerr RS \& Milford CA Minimally invasive biopsy of parasellar lesions: safety and clinical applications of the endoscopic, transnasal approach. British Journal of Neurosurgery 19 338-344, 2005 18.Samii M, Gerganov VM. Surgery of extra-axial tumors of the cerebral base. Neurosurgery. (Suppl 3):1153-61, 2008

19.Shulev, Yuri; Akobyan, Ovanes Pterional Approach to Management of Anterior Skull Base MeningiomasSkull Base; Issue 03, 2009

20.Stanila A, Florian IS et al, Ghid de Neurooftalmologie, Edit. Universitatii L.Blaga Sibiu, 2007; 54-78

21.Yaşargil MG, Curcic M, Kis M, Siegenthaler G, Teddy PJ, Roth P: Total removal of craniopharyngiomas. Approaches and long-term results in 144 patients. J Neurosurg 73:3-11, 1990

22..Yasargil MG, Krisht AF, Türe U, Al-Mefty O, Yasargil DCH. Microsurgery of insular gliomas: Part I. Surgical anatomy of the Sylvian cistern. Contemporary Neurosurgery 2002; 24:1-8.

23. Wen HT, Oliveira E, Tedeschi H, Andrade FC, Rhoton AL. The pterional approach: Surgical anatomy, operative technique, and rationale. Operat TechNeurosurgery 2001; 4:60-72. 